\title{
Nutraceuticals for Knee Osteoarthritis Pain Relief. Results from a Preliminary Randomised Clinical Trial
}

\author{
Evdokia Valsamidou ${ }^{1,2}$, Charalampia Amerikanou ${ }^{1}$, Chara Tzavara ${ }^{1}$, Panagiotis Zoumpoulakis ${ }^{3,4}$, \\ Theodoros D. Mariolis-Sapsakos ${ }^{5}$, George Skarpas ${ }^{6}$ and Andriana C. Kaliora ${ }^{1, *}$ \\ 1 Department of Nutrition and Dietetics, School of Health Science and Education, Harokopio University, \\ 70 El Venizelou Ave., 17677 Athens, Greece; evdokiavalsamidou@gmail.com (E.V.); \\ amerikanou@windowslive.com (C.A.); htzavara@med.uoa.gr (C.T.) \\ 2 Qualia Pharma, 2 Kalavriton, Kifissia, 14564 Athens, Greece \\ 3 Department of Food Science and Technology, University of West Attica, Ag. Spyridonos, Egaleo, \\ 12243 Athens, Greece; pzoump@uniwa.gr \\ 4 Institute of Chemical Biology, National Hellenic Research Foundation, 48 Vas. Constantinou Ave., \\ 11635 Athens, Greece \\ 5 Laboratory of Anatomy, School of Nursing, University of Athens, 123 Papadiamantopoulou Str., Goudi, \\ 11527 Athens, Greece; tmariolis@nurs.uoa.gr \\ 6 Evgenidio Clinic Agia Trias, 20 Papadiamantopoulou Str., Ilissia, 11852 Athens, Greece; skarpasg@gmail.com \\ * Correspondence: akaliora@hua.gr; Tel.: +30-210-954-9226
}

\section{check for}

updates

Citation: Valsamidou, E.; Amerikanou, C.; Tzavara, C.; Zoumpoulakis, P.; MariolisSapsakos, T.D.; Skarpas, G.; Kaliora, A.C. Nutraceuticals for Knee Osteoarthritis Pain Relief. Results from a Preliminary Randomised Clinical Trial. Dietetics 2022, 1, 2-14. https://doi.org/10.3390/

dietetics 1010002

Academic Editor: Dariusz Nowak

Received: 21 October 2021

Accepted: 24 November 2021

Published: 30 November 2021

Publisher's Note: MDPI stays neutral with regard to jurisdictional claims in published maps and institutional affiliations.

Copyright: (c) 2021 by the authors. Licensee MDPI, Basel, Switzerland. This article is an open access article distributed under the terms and conditions of the Creative Commons Attribution (CC BY) license (https:// creativecommons.org/licenses/by/ $4.0 /)$.

\begin{abstract}
Osteoarthritis is the most common inflammation-based joint disease. Polyphenols are plant secondary metabolites with established antioxidant and anti-inflammatory properties. Recognizing the need for holistic approaches in the management of knee osteoarthritis, we designed a two-arm, randomised clinical trial to evaluate the efficacy of a supplement rich in phenolic compounds in OA. Primary outcomes included changes in Visual Analog Scale (VAS) and Western Ontario and McMaster Universities Osteoarthritis (WOMAC) pain subscale. Secondary outcome measures were the changes in WOMAC stiffness and functionality subscales. Patients were randomised (1:1) to receive a mixture of phenolic compounds and ascorbic acid (PhAA,) or ascorbic acid (AA). Medical history, biochemical profile and anthropometric measurements were obtained. Eighty-six patients were screened and 25 were randomly allocated in a pilot study to receive a mixture of phenolic compounds and ascorbic acid (PhAA,) or ascorbic acid (AA) adjunct to stable medical treatment. The nutraceutical supplements were well tolerated and no adverse events were reported. VAS decreased in the PhAA group $(p<0.001)$. Additionally, WOMAC composite score decreased significantly only in the PhAA group $(p<0.05)$. The WOMAC subscale of pain decreased in both treatment groups ( $p=0.001$ for the PhAA group, $p<0.05$ for the AA group). The decrease in the subscales of stiffness and physical function was not significant for either group. A possible improvement in the quality of life of these patients using nutraceutical supplements is apparent. Although preliminary, our positive results support the hypothesis that treatment with nutraceuticals may be effective for pain relief in osteoarthritis. ClinicalTrials.gov Identifier: NCT04783792.
\end{abstract}

Keywords: knee osteoarthritis; polyphenols; RCT design; nutraceuticals; pain relief; antioxidant

\section{Introduction}

Osteoarthritis (OA) is the most common joint malady and one of the major debilitating diseases, with an increasing social burden for most countries owing to the aging of the population. The global prevalence increased 9.3\% from 1990 to 2017 with greater affliction on the female sex [1]. A comprehensive understanding of the risk factors and the long-term advantages of the management of OA, while abolishing social disparities that may inhibit proper access to health services, is of paramount importance.

OA affects the whole joint and is strongly mediated by age-related cellular senescence [2], genetics, and injury/malalignment [3], and is possibly exacerbated and/or 
induced by obesity and metabolic syndrome [4,5]. A stress stimulus can trigger innate immunity [6] and is partly due to the unique physiology of the articular cartilage inflammation that is sustained [7] in a catabolic, oxidative environment [8]. The activation of detrimental molecular cascades creates feedback loops that further contribute to the degradation and ossification of the cartilage, the inflammation of the synovium, and the formation of osteophytes.

In the non-pharmacological realm, the management of OA consists of changes to the patient's lifestyle i.e., exercise, loss of weight and bracings for knee OA [9]. On the other hand, the current pharmacological treatment of OA cardinal symptoms, such as pain, stiffness and oedema, includes an array of slow-acting drugs [10], including glucosamine sulfate, chondroitin sulfate, avocado soybean unsaponifiables, and rapid-acting drugs; non-steroidal anti-inflammatory drugs (NSAIDs). Morbidities such as gastrointestinal disorders, cardiovascular diseases and frailty are a common finding in OA, and even though non-selective NSAIDs, adjunct to proton pump inhibitors, and COX-2 inhibitors are a first-line treatment, revised recommendations by OARSI propose an approach that takes into account concomitant pathologies by using intra-articular injections of corticosteroids for acute pain relief and hyaluronic acid for a longer treatment effect as monotherapies [11].

In the context of new therapeutic approaches emerging in the health system owing to the COVID-19 pandemic [12], and considering the increased burden of OA, existing promising treatments need to be refined and thoroughly elucidated in order to be adopted by the guidelines into the clinical practice. To this end, disease-modifying OA drugs [13-15], monoclonal antibodies $[16,17]$ and autologous treatments such as chondrocyte implantation, mesenchymal stem cells and platelet-rich plasma comprise some alternative options [18]. However, since OA is a multifactorial disease with progressive development, it renders the aforementioned treatments limited in regards to the times that they can be employed [19] and the therapeutic impact that they may have. The quest for more effective and side effect-free treatment for OA has rendered nutraceutical and pharmaceutical supplements as an auxiliary treatment for OA [20].

Plant-derived polyphenols are a class of phytochemicals that have been extensively evaluated as potent antioxidant and anti-inflammatory agents in OA [21] in preclinical models [22] and to some extent in clinical trials. Notably, RCTs in patients with OA have investigated the polyphenol intake from different food items and extracts [23-34]. For example, pain and serum levels of inflammatory markers were decreased in knee OA patients receiving $500 \mathrm{mg}$ of resveratrol as adjunct to their therapy for 12 weeks [35]. In a pilot randomized double-blind placebo-controlled clinical trial, patients with knee OA receiving curcuminoids for 6 weeks experienced significantly greater reductions in pain scores compared to those receiving placebo [28]. The consumption of a high-rosmarinic acid spearmint tea for 16 weeks significantly decreased pain scores in patients with knee OA compared to the consumption of a commercially available spearmint tea [26].

The combination of polyphenols, which have established beneficial anti-inflammatory and antioxidant properties, in a supplement with optimal characteristics in regard to their concentration and bioavailability, represents a promising and novel approach in the dietary management of OA. From this perspective, and recognizing the need for more RCTs, we designed a two-arm, parallel-design, double-blind, randomized controlled trial of the efficacy of an innovative phytochemical-rich supplement relative to ascorbic acid (AA) that was already on the market and is considered an analgesic against musculoskeletal pain. Herein, we present the first evidence comparator study with the objective of assessing the results in the changes of pain as assessed by Visual Analog Scale (VAS) and Western Ontario and McMaster Universities Osteoarthritis (WOMAC) pain subscale.

\section{Materials and Methods}

\subsection{Supplements}

The nutraceutical supplement tested herein (Patent number: 20210100519/30-07-2021) contained a combination of plant phytoconstituents, mainly natural phenols and ascorbic 
acid (PhAA), curcuma phospholipids (148.4 mg), rosemary extract $(51.9 \mathrm{mg})$, resveratrol extract 95\% (51.9 mg), ascorbic acid (29.7 mg), VIVAPHARM ${ }^{\circledR}$ HPMC E50 -Hypromellose, and magnesium stearate. The comparator was ascorbic acid (AA, $29.7 \mathrm{mg}$ ). The polyphenols employed in this novel supplement have extensively been evaluated with regard to the management of OA [22,26-29] and their structures are presented in Figure 1. Curcumin is the main curcuminoid of the plant Curcuma longa, of the Zingiberaceae family. The therapeutic activities of curcumin are hindered by its unstable nature and low bioavailability. To maximize the potency of this polyphenol, we encapsulated it in phytosomes, a promising technology for the development of new drugs. Resveratrol, mainly present in the skin of the grapes, is a stilbene, a non-flavonoid polyphenol that is a multi-potent molecule with anti-inflammatory, antioxidant and anti-aging properties. Finally, rosmarinic acid is an ester of caffeic and 3,4-dihydroxyphenyllactic acid and can be found in herbs such as rosemary, basil and oregano. Its pharmacological activities include antiviral, antibacterial and neuroprotective effects.<smiles>[R]Oc1cc(/C=C/C(=O)/C=C(O)/C=C/c2ccc(O)c(OC)c2)ccc1O</smiles><smiles>O=C(/C=C/c1ccc(O)c(O)c1)O[C@@H](Cc1ccc(O)c(O)c1)C(=O)O</smiles>

Rosmarinic acid

Figure 1. Chemical structures of the phenolic compounds in the tested supplement.

\subsection{Ethics}

Harokopio University Ethics Committee (13/21-2-2020) and Evgenidio Hospital Scientific Board (29/19-02-2019) approved the study design and protocol, which was designed according to the principles of the Declaration of Helsinki and the Data Protection Act 1998.

\subsection{Study Design}

Patients were invited to participate in the trial in the orthopaedic outpatient clinic of Evgenidio Hospital in Athens from November 2020 to February 2021. After clinical evaluation of the patients from the orthopaedic doctor of the study and upon confirmation that they met the inclusion/exclusion criteria, the patients were thoroughly informed about the study protocol and those who were interested in participating signed informed consent, knowing that it was not by any means binding.

The inclusion criteria were male or female patients above the age of 35 with monolateral or bilateral knee OA confirmed by radiographic measurements (stage II, III or IV according to Kellgren-Lawrence, $\mathrm{K} \& \mathrm{~L}$ ), with at least moderate symptoms in the target knee that translated as intermittent or constant pain above 4 in the WOMAC pain subscale and in VAS, that were able to walk without a medical or other support device (such as a 
walking stick, crutches, or a kneecap). In bilateral knee OA, the target knee was determined as the knee with highest VAS pain score.

The exclusion criteria were patients undergoing physical therapy or transcutaneous electrical nerve stimulation (TENS), with rheumatoid arthritis, fibromyalgia, spinal disorders or any other musculoskeletal disorders that according to the physician was a bias, with a scheduled knee surgery or any other programmed surgery during the trial, those with a diagnosis of kidney or liver disease, coagulation disorders, any form of cancer, HIV infection, type I diabetes, those with unregulated type II diabetes, those using illicit substances or with a history of substance or alcohol abuse over the past 2 years (or those who consume more than 2 typical alcoholic beverages/day at present), those using corticosteroids within 2 months prior to randomisation and during the trial, those who changed their diet or supplementation 1 month prior or during the recruitment/trial, those using AA supplement or any phytochemical-rich supplement, women on oestrogen-replacement therapy, pregnant or lactating and those judged by the researcher as unable to perceive and comply with the obligations laid down in the protocol for which consent and voluntary participation was sought.

On intense pain, patients were allowed to use rescue medication, either analgesics or non-steroidal anti-inflammatory drugs (NSAIDs), as prescribed by the study physician.

The study has been registered with the ClinicalTrials.gov Identifier: NCT04783792.

\subsection{Baseline Assessment \& Outcome Measures}

A complete medical history with information about the demographic characteristics of the patients, habits that affected their general health (smoking, alcohol), heredity data, age at diagnosis, the cause of the onset of the disease, current medication/supplementation and surgeries was collected.

Anthropometric measurements, such as height $(\mathrm{cm})$, body weight $(\mathrm{kg})$, as well as waist circumference $(\mathrm{cm})$, measured with a flexible non-stretch tape halfway between the lower ribs and the iliac crest, and hip circumference $(\mathrm{cm})$, measured at the level of the widest circumference over the great trochanters, for the calculation of waist-hip ratio (WHR), were obtained. Estimation of body composition (fat $\%$, fat mass and lean mass) was performed through bioelectrical impedance analysis (BIA). Body weight was measured to the nearest $0.1 \mathrm{~kg}$. Height was measured to the nearest millimetre and body mass index (BMI) was computed as weight $(\mathrm{kg}) /$ height $(\mathrm{m})^{2}$.

For the assessment of pain, the validated pain VAS, a numeric scale from 0 (no pain) to $10 \mathrm{~cm}$ (worst pain), was used to depict the worst feeling of pain the patient had the day before the interview or in the last week. Additionally, the Greek-validated WOMAC questionnaire was also employed as its three dimensions, pain ( 5 items), stiffness ( 2 items) and functional limitations (17 items), reflect the severity of the cardinal symptoms of OA. Higher scores indicate worse symptoms [36].

After completing the baseline assessment, the patients were randomly assigned to one of the following arms: a mixture of phenolic compounds and ascorbic acid (PhAA), or AA. Sample 1:1 randomisation was performed using an algorithm that allocated subjects to the two arms of the intervention based on their gender and age. The per os administration dosage was two capsules daily, taken approximately $20 \mathrm{~min}$ before meals. In order to mitigate biases, blinding of the involved researchers, as well as the volunteers, was ensured through the identical containers and organoleptic characteristics of the capsules.

Changes in lifestyle or medication, general health status and possible occurrence of adverse effects were monitored biweekly via telephone calls. The participants' compliance with the protocol was based on subject self-reporting and pill count. After 8 weeks, VAS and WOMAC were re-evaluated. The primary outcome measures were the changes in WOMAC pain subscale and VAS. The secondary outcome measures were the changes in WOMAC stiffness and functionality subscales. 


\subsection{Statistical Analysis}

Quantitative variables were expressed as mean values (SD), while qualitative variables were expressed as absolute and relative frequencies. Quantitative variables were tested for normality using the Kolmogorov-Smirnov criterion. For the comparison of proportions, Fisher's exact tests were used. For the comparison of means between two groups, Student's $t$-tests were used. Repeated measurements analysis of variance (ANOVA) was adopted to evaluate the changes observed in VAS and WOMAC scales between the two treatment groups over the follow-up period. All reported $p$ values are two-tailed. Statistical significance was set at $p<0.05$. Analyses were conducted using SPSS statistical software (version 22.0).

The primary outcome of the trial was a significant reduction in pain in OA patients. Pain measure is a patient-reported outcome, particularly common for treatments developed for conditions where intentions are to ameliorate symptoms, facilitate functioning and improve quality of life. The data derived can be used to measure the benefit and risk of a treatment, such as any side effects or inconvenience. Furthermore, we aimed to determine the population size of our ongoing prospective randomised controlled trial based on the preliminary outcomes of measures of pain.

\section{Results}

\subsection{Allocation \& Demographics}

Initially, from the 86 patients that were assessed for eligibility, 35 were excluded in accordance with the inclusion/exclusion criteria. The remaining 51 patients gave an informed consent, but 26 declined to participate, mostly owing to the pandemic. Finally, 25 patients were randomised to receive the allocated intervention, either AA $(N=12)$ or PhAA $(N=13)$. Since 2 patients were lost to follow-up and 1 patient did not start the allocated intervention for personal reasons, data from 22 patients were analysed (Figure 2). Sample characteristics of the 25 participants with a mean age of 60.5 years $(\mathrm{SD}=11.1)$ are presented in Table 1. The two study groups were similar in terms of demographics and clinical characteristics.

\subsection{Adverse Events and Use of Rescue Medication}

Generally, the two interventions were well-tolerated and the occurrence of adverse events was not attributed to the treatment. Specifically, one volunteer from the PhAA group suffered from a fracture of the left ankle and two volunteers from the AA group reported a mild rash on the left arm and forehead that subsided after 3 days and a heart attack, respectively. With the exception of the heart attack patient who discontinued the supplementation at two months owing to hospitalization, the other two patients followed the protocol normally. Herein, $72.7 \%$ of the patients who received the nutraceutical supplement reported a decrease in use of rescue medication compared with $54.4 \%$ of the patients receiving the comparator supplement, indicative of the pain relief effect of the phenolic compounds in OA.

\subsection{WOMAC}

As presented in Table 2, there were no significant differences in composite WOMAC and its subscales between the two groups at baseline. At follow-up, scores of pain decreased significantly in both groups ( $p=0.001$ for group PhAA, $p=0.027$ for group AA), but patients in the PhAA group had significantly lower levels of pain at follow-up as compared to patients in the AA group $(p=0.039)$. Stiffness and physical function were not significantly changed, but score in the composite dimension was decreased significantly only in the PhAA group $(p=0.033)$. 


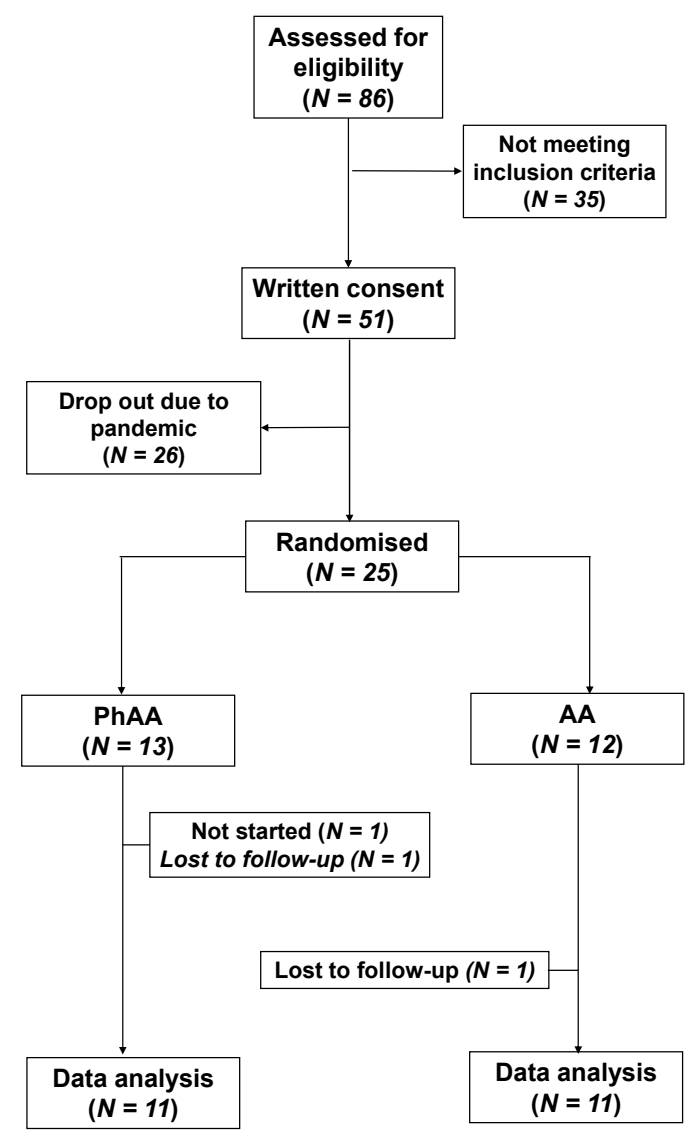

Figure 2. Flow diagram of the study.

Table 1. Demographics, anthropometrics and clinical characteristics of OA patients that participated in the study. The results are given as $N(\%)$ of the total number or mean (SD).

\begin{tabular}{|c|c|c|c|}
\hline & \multicolumn{2}{|c|}{ Treatment } & \multirow{3}{*}{$p$} \\
\hline & $\begin{array}{c}\text { AA } \\
N=12\end{array}$ & $\begin{array}{l}\text { PhAA } \\
N=13\end{array}$ & \\
\hline & $N(\%)$ & $N(\%)$ & \\
\hline \multicolumn{4}{|l|}{ Sex } \\
\hline Men & $4(33.3)$ & $5(38.5)$ & $1.000++$ \\
\hline Women & $8(66.7)$ & $8(61.5)$ & \\
\hline Age (years), mean (SD) & $60.6(11.9)$ & $60.4(10.9)$ & $0.966+$ \\
\hline \multicolumn{4}{|l|}{ Marital status } \\
\hline Married, divorced & 11 (91.7) & $10(76.9)$ & $0.593++$ \\
\hline Unmarried & $1(8.3)$ & $3(23.1)$ & \\
\hline \multicolumn{4}{|l|}{ Education } \\
\hline 1-9 years & $4(33.3)$ & $3(23.1)$ & $0.358++$ \\
\hline $10-12$ years & $3(25.0)$ & $1(7.7)$ & \\
\hline$>12$ years & $5(41.7)$ & $9(69.2)$ & \\
\hline \multicolumn{4}{|l|}{ Smoking } \\
\hline No & $7(58.3)$ & $11(84.6)$ & $0.202++$ \\
\hline Yes & $5(41.7)$ & $2(15.4)$ & \\
\hline Fat $\%$, mean $(\mathrm{SD})$ & $38.2(9.1)$ & $30.5(10.5)$ & $0.096+$ \\
\hline BMI $\left(\mathrm{kg} / \mathrm{m}^{2}\right)$, mean $(\mathrm{SD})$ & $32.2(6.1)$ & $28.7(4.7)$ & $0.119+$ \\
\hline WHR, mean (SD) & $0.91(0.08)$ & $0.92(0.06)$ & $0.731+$ \\
\hline \multicolumn{4}{|l|}{ K\&L (disease severity) } \\
\hline 2 & $1(8.3)$ & $4(30.8)$ & $0.119++$ \\
\hline 3 & $5(41.7)$ & $7(53.8)$ & \\
\hline 4 & $6(50.0)$ & $2(15.4)$ & \\
\hline
\end{tabular}

+ Student's $t$-test; ++ Fisher's exact test, AA: ascorbic acid, PhAA: polyphenols + AA, BMI: body mass index, WHR: waist-hip ratio, K\&L: Kellgren \& Lawrence. 
Table 2. Changes in WOMAC scales during the follow-up for the two study groups. Values are expressed as the mean (SD).

\begin{tabular}{|c|c|c|c|c|c|}
\hline \multirow{2}{*}{ Treatment } & \multicolumn{2}{|c|}{ Baseline } & \multicolumn{2}{|c|}{ Follow-up } & \multirow{2}{*}{$p^{2}$} \\
\hline & Mean & SD & Mean & SD & \\
\hline \multicolumn{6}{|l|}{ WOMAC (pain) } \\
\hline $\mathrm{AA}$ & 8.92 & 3.09 & 6.30 & 3.08 & 0.027 \\
\hline PhAA & 7.31 & 3.84 & 3.60 & 3.09 & 0.001 \\
\hline$p^{1}$ & \multicolumn{2}{|c|}{0.263} & \multicolumn{2}{|c|}{0.039} & \\
\hline \multicolumn{6}{|l|}{ WOMAC (stiffness) } \\
\hline $\mathrm{AA}$ & 2.08 & 1.83 & 1.45 & 1.51 & 0.071 \\
\hline $\mathrm{PhAA}$ & 1.54 & 1.66 & 1.30 & 1.34 & 0.278 \\
\hline$p^{1}$ & \multicolumn{2}{|c|}{0.549} & \multicolumn{2}{|c|}{0.807} & \\
\hline \multicolumn{6}{|c|}{ WOMAC (physical function) } \\
\hline AA & 27.08 & 13.72 & 21.18 & 9.21 & 0.335 \\
\hline PhAA & 17.15 & 10.55 & 15.30 & 12.97 & 0.182 \\
\hline$p^{1}$ & \multicolumn{2}{|c|}{0.395} & \multicolumn{2}{|c|}{0.242} & \\
\hline \multicolumn{6}{|l|}{ WOMAC (composite) } \\
\hline AA & 39.66 & 17.83 & 29.35 & 12.83 & 0.100 \\
\hline PhAA & 26.84 & 15.58 & 19.22 & 15.40 & 0.033 \\
\hline$p^{1}$ & \multicolumn{2}{|c|}{0.283} & \multicolumn{2}{|c|}{0.109} & \\
\hline
\end{tabular}

${ }_{1}^{1} p$-value for group effect; ${ }^{2} p$-value for time effect; significant values in bold; AA: ascorbic acid, PhAA: polyphenols + ascorbic acid, WOMAC: Western Ontario McMaster Osteoarthritis Index.

\subsection{VAS}

Changes in pain as measured with VAS are shown in Table 3. Subjects in the PhAA group reported a significant decrease in pain $(p<0.001)$, while pain remained stable for patients in the AA group $(p>0.999)$, resulting in a significant interaction effect in repeated measurements analysis of variance $(p<0.001)$ (data not shown). In addition, at follow up, patients in the PhAA group reported significantly lower levels of pain as compared to those in the AA group $(p=0.017)$.

Table 3. VAS at baseline and at follow-up for the two study groups. Values are expressed as the mean (SD).

\begin{tabular}{|c|c|c|c|c|c|}
\hline \multirow{3}{*}{ Treatment } & \multicolumn{4}{|c|}{ VAS } & \multirow{3}{*}{$p^{2}$} \\
\hline & \multicolumn{2}{|c|}{ Baseline } & \multicolumn{2}{|c|}{ Follow-up } & \\
\hline & Mean & SD & Mean & SD & \\
\hline AA & 6.13 & 1.94 & 6.00 & 1.57 & $>0.999$ \\
\hline PhAA & 7.04 & 2.02 & 3.92 & 2.24 & $<0.001$ \\
\hline$p^{1}$ & 0.261 & 0.017 & & & \\
\hline
\end{tabular}

${ }_{1} p$-value for group effect; ${ }^{2} p$-value for time effect; significant values in bold; AA: ascorbic acid PhAA: polyphenols + ascorbic acid, VAS: visual analogue scale.

\subsection{Sample Size}

Based on the above, we conducted power analysis with two levels of the betweensubject factor of two study groups and two levels of the within-subjects factor of time. Based on our data herein, a repeated-measures ANOVA power analysis was conducted. The power analysis was conducted for a single, two-group between-subjects factor, and a single within-subjects factor assessed over two time points. For our design, 52 participants (26 per group) achieved a power of 0.95 for the within-subjects main effect at an effect size of 0.26 , a power of 0.85 for the between-subjects main effect at an effect size of 0.38 and a power of 0.95 for the interaction effect at an effect size of 0.26 . Taking into account a 
dropout of $20-25 \%$ for any reason, the required sample size for the design of the main RCT was estimated at 72 patients.

\section{Discussion}

During a recruitment period of 3 months, we were able to randomise 25 patients to either PhAA or comparator, with $22(88 \%)$ of them eligible for a per protocol analysis. Furthermore, based on the results of this initial design, we performed a sample size calculation that estimated a final RCT sample of 72 patients. Our trial provided new evidence for the efficacy of a PhAA supplement on pain, the main debilitating symptom of OA. However, the changes in WOMAC dimensions and total score showed no difference; the pain VAS that was applied as a subjective measure of pain intensity was significantly decreased in PhAA but remained unchanged in AA.

The selection of clinically important outcomes in an OA trial is challenging given the fact that its pathophysiology, presented as joint space narrowing, osteophytes and bone cysts, does not correlate well with the clinical manifestation of its symptoms such as pain [37]. The major two entities implicated in OA pain are bone marrow lesions and synovitis, inflammation of the synovial membrane [38]. Changes in the perception of pain are frequently used as first-line indicators of the course of an intervention. However, there is great heterogeneity in pain sensitivity that can be attributed to person-level factors i.e., psychological and the individual's pain thresholds, and systemic-level factors summed up in the delicate balance between nociceptive pain, neuropathic pain and the affected joint [39,40]. Carlesso et al. [41] proposed the identification of a pain susceptibility phenotype to shed light to the transition from acute pain to chronic as a new means of managing more efficiently pain in symptomatic OA in the context of pre-emptive therapy.

The available data support the intake of polyphenols for the management of pain in OA, not only as they have anti-inflammatory and antioxidant properties but also anticatabolic effects, attributes that render them ideal to be used combined in the form of nutraceuticals [42]. However, polyphenol-rich supplements that have been evaluated in clinical trials in OA are limited.

Pycnogenol, a flavonoid-rich extract from the bark of Pinus maritime, has been evaluated in three knee OA randomised trials controlled with placebo. Farid et al. [30] demonstrated that patients receiving pycnogenol for three months showed significant improvement in composite WOMAC score and its subscales and the use of NSAIDs or cyclooxygenase-2 (COX-2) inhibitors was significantly reduced compared to placebo. Similarly, in larger cohorts Cisar et al. [43] reported a significant decrease in WOMAC scores and VAS compared to placebo, and Belcaro et al. [44] showed a decrease in plasma C-reactive protein in patients treated with pycnogenol. Mechanistically, the anti-inflammatory action of pycnogenol may be achieved by the inhibition of nuclear factor kappa-B (NF-kB)mediated pro-inflammatory cascades and of COX enzymes $[45,46]$.

Another supplement, rich in the flavonoids catechin and baicalin from the extracts of Scutellaria baicalensis and Acacia catechu, named flavocoxid, was as effective as naproxen in two clinical trials $[33,47]$ that evaluated pain and functionality through WOMAC and VAS. The beneficial effect was attained by the inhibition of inflammatory enzymes such as COX-1, COX-2 and 5-lipoxygenase (5-LOX) [48,49].

A recent clinical trial [29] investigated the effect of the combination of curcumin (turmeric), gingerol (ginger) and pyrene (black pepper) against naproxen in moderate knee OA. Serum levels of the inflammatory mediator prostaglandin $\mathrm{E}_{2}\left(\mathrm{PGE}_{2}\right)$ were determined before and after the 8-week treatment and the results showed a significant decrease for both groups.

AA is a water-soluble vitamin that induces the synthesis of the basic molecules of the cartilage, as shown in vitro. Collagen, aggrecan $[50,51]$ and optimal vitamin $C$ intake are thought to be protective against OA initiation [52]. Furthermore, knee pain in bone marrow lesions [53] had a negative correlation with higher vitamin $C$ intake in a prospective cohort of healthy subjects [54]. Despite the regulatory role that AA seems to play in bone and 
cartilage metabolism and its analgesic properties against musculoskeletal pain [55], its antioxidant capacity may be responsible for the conflicting results in regard to the positive correlation between higher intake of AA and radiographic knee OA [56,57]. AA was also chosen to be added in this supplement as it is known for its antioxidant activity and its addition may have a positive influence on the quality, stability and antioxidant capacity of some polyphenols [58]. For example, the antioxidant activity of curcumin in vitro seems to be increased by the addition of ascorbic acid [59].

In this study, AA was chosen as the reference intervention to the active comparator PhAA in order to provide benefit to the patients and to avoid ethical implications that would arise from not treating a painful debilitating disease such as OA [60]. AA was also used in a 2008 RCT that evaluated Garcinia kola seeds, high in bioflavonoid compounds, in knee OA [61]. After a 6-week intervention with Garcinia kola, WOMAC pain and VAS score were significantly decreased compared to placebo $(p<0.001)$. Furthermore, intake of the supplement caused a faster onset of pain relief and longer duration of the beneficial effect when compared to placebo. These findings of the superiority of a flavonoid-rich supplement against AA are corroborated by our preliminary results.

There are some limitations to this trial. Firstly, owing to the nature of the preliminary results, the sample size is small and does not allow for extrapolation of the findings. Furthermore, the self-reported compliance to the study protocol, the ad libitum intake of analgesics and the concomitant intake of health supplements are possible confounding factors.

These promising findings may be due to the synergistic and/or additive attributes of the polyphenols. Such relationships between the constituents are hard to define and quantify, but indications of their existence, mostly in pre-clinical models, are a driving force towards more research in that field. The results presented herein support the hypothesis that treatment with nutraceuticals may be effective, particularly as related to the feeling of pain. Our data depict the effect of the combination of nutraceuticals with established anticatabolic, anti-inflammatory and antioxidant mechanisms of action against knee OA pain.

\section{Conclusions}

The preliminary results of this study support the hypothesis that treatment with the newly introduced multi-compound supplement was effective, as reflected by the selfreported feeling of pain. Taking into consideration the findings of this pilot trial in the design of the main RCT, we believe that upon the completion of the larger trial, more solid findings are expected in regards not only with pain but also with biomarkers of inflammation and oxidation.

\section{Patents}

Patent number: 20210100519/30-07-2021.

Author Contributions: Conceptualization, A.C.K.; Formal analysis, C.T.; Investigation, E.V., C.A.; writing-original draft preparation, E.V. and C.A.; writing-review and editing, E.V., C.A., G.S., P.Z., T.D.M.-S., A.C.K. All authors have read and agreed to the published version of the manuscript.

Funding: This work was co-financed by the European Regional Development Fund of the European Union and Greek national funds through the Operational Program Competitiveness, Entrepreneurship and Innovation, under the call RESEARCH-CREATE-INNOVATE (project code: T1E $\Delta K-01921$, Next Generation Food Supplements).

Institutional Review Board Statement: The study was conducted according to the guidelines of the Declaration of Helsinki, and approved by the Institutional Review Board of Evgenidio Hospital (29/19-02-2019) and the Ethics Committee of Harokopio University (13/21-2-2020). 
Informed Consent Statement: Informed consent was obtained from all subjects involved in the study.

Data Availability Statement: The data presented in this study are available on request from the corresponding author.

Acknowledgments: We are grateful to the patients for participating in this study. The dietary supplement used in the present study will be commercialized by Qualia Pharma SA under the brand name "Arthro Relief". All authors consent to the acknowledgments.

Conflicts of Interest: Author E.V. is an employee of Qualia Pharma but owns no shares in the company. The funding source provided the supplements and did not have any role in study design, collection, analysis, interpretation of the data or decision to submit this manuscript. The remaining authors declare no conflict of interest.

\begin{tabular}{|c|c|}
\hline $\mathrm{OA}$ & osteoarthritis \\
\hline RCT & randomized controlled trial \\
\hline VAS & visual analog scale \\
\hline WOMAC & Western Ontario and McMaster Universities Osteoarthritis \\
\hline AA & ascorbic acid \\
\hline PhAA & polyphenols $+\mathrm{AA}$ \\
\hline TENS & transcutaneous electrical nerve stimulation \\
\hline K\&L & Kellgren \& Lawrence \\
\hline WHR & waist-hip ratio \\
\hline BIA & bioelectrical impedance analysis \\
\hline BMI & body mass index \\
\hline $\operatorname{cox}$ & cyclooxygenase \\
\hline$N F-\kappa B$ & nuclear factor kappa-B \\
\hline $\mathrm{PGE}_{2}$ & prostaglandin $\mathrm{E}_{2}$ \\
\hline
\end{tabular}

\section{References}

1. Safiri, S.; Kolahi, A.A.; Smith, E.; Hill, C.; Bettampadi, D.; Mansournia, M.A.; Hoy, D.; Ashrafi-Asgarabad, A.; Sepidarkish, M.; Almasi-Hashiani, A.; et al. Global, regional and national burden of osteoarthritis 1990-2017: A systematic analysis of the Global Burden of Disease Study 2017. Ann. Rheum. Dis. 2020, 79, 819-828. [CrossRef]

2. Hou, A.; Chen, P.; Tang, H.; Meng, H.; Cheng, X.; Wang, Y.; Zhang, Y.; Peng, J. Cellular senescence in osteoarthritis and anti-aging strategies. Mech. Ageing Dev. 2018, 175, 83-87. [CrossRef]

3. Palazzo, C.; Nguyen, C.; Lefevre-Colau, M.M.; Rannou, F.; Poiraudeau, S. Risk factors and burden of osteoarthritis. Ann. Phys. Rehabil. Med. 2016, 59, 134-138. [CrossRef]

4. Berenbaum, F.; Eymard, F.; Houard, X. Osteoarthritis, inflammation and obesity. Curr. Opin. Rheumatol. 2013, 25, 114-118. [CrossRef]

5. Courties, A.; Sellam, J.; Berenbaum, F. Metabolic syndrome-associated osteoarthritis. Curr. Opin. Rheumatol. 2017, 29 , 214-222. [CrossRef] [PubMed]

6. Woodell-May, J.E.; Sommerfeld, S.D. Role of Inflammation and the Immune System in the Progression of Osteoarthritis. J. Orthop. Res. 2020, 38, 253-257. [CrossRef] [PubMed]

7. Robinson, W.H.; Lepus, C.; Wang, Q.; Raghu, H.; Mao, R.; Lindstrom, T.M.; Sokolove, J. Low-grade inflammation as a key mediator of the pathogenesis of osteoarthritis. Nat. Rev. Rheumatol. 2016, 12, 580-592. [CrossRef]

8. Lepetsos, P.; Papavassiliou, A.G. ROS/oxidative stress signaling in osteoarthritis. Biochim. Biophys. Acta 2016, $1862,576-591$. [CrossRef]

9. Kolasinski, S.L.; Neogi, T.; Hochberg, M.C.; Oatis, C.; Guyatt, G.; Block, J.; Callahan, L.; Copenhaver, C.; Dodge, C.; Felson, D.; et al. 2019 American College of Rheumatology/Arthritis Foundation Guideline for the Management of Osteoarthritis of the Hand, Hip, and Knee. Arthritis Care Res. 2020, 72, 149-162. [CrossRef] [PubMed]

10. Honvo, G.; Reginster, J.Y.; Rabenda, V.; Geerinck, A.; Mkinsi, O.; Charles, A.; Rizzoli, R.; Cooper, C.; Avouac, B.; Bruyère, O. Safety of Symptomatic Slow-Acting Drugs for Osteoarthritis: Outcomes of a Systematic Review and Meta-Analysis. Drugs Aging 2019, 36, 65-99. [CrossRef]

11. Bannuru, R.R.; Osani, M.C.; Vaysbrot, E.E.; Arden, N.K.; Bennell, K.; Bierma-Zeinstra, S.M.A.; Kraus, V.B.; Lohmander, L.S.; Abbott, J.H.; Bhandari, M.; et al. OARSI guidelines for the non-surgical management of knee, hip, and polyarticular osteoarthritis. Osteoarthr. Cartil. 2019, 27, 1578-1589. [CrossRef] [PubMed]

12. Ragni, E.; Mangiavini, L.; Viganò, M.; Brini, A.T.; Peretti, G.M.; Banfi, G.; de Girolamo, L. Management of Osteoarthritis during the COVID-19 Pandemic. Clin. Pharmacol. Ther. 2020, 108, 719-729. [CrossRef] 
13. Hochberg, M.C.; Guermazi, A.; Guehring, H.; Aydemir, A.; Wax, S.; Fleuranceau-Morel, P.; Bihlet, A.R.; Byrjalsen, I.; Andersen, J.R.; Eckstein, F. Effect of Intra-Articular Sprifermin vs Placebo on Femorotibial Joint Cartilage Thickness in Patients with Osteoarthritis: The Forward Randomized Clinical Trial. JAMA 2019, 322, 1360-1370. [CrossRef]

14. Conaghan, P.G.; Bowes, M.A.; Kingsbury, S.R.; Brett, A.; Guillard, G.; Rizoska, B.; Sjögren, N.; Graham, P.; Jansson, Å.; Wadell, C. Disease-Modifying Effects of a Novel Cathepsin K Inhibitor in Osteoarthritis: A Randomized Controlled Trial. Ann. Intern. Med. 2020, 172, 86-95. [CrossRef]

15. McClurg, O.; Tinson, R.; Troeberg, L. Targeting Cartilage Degradation in Osteoarthritis. Pharmaceuticals 2021, 14, 126. [CrossRef] [PubMed]

16. Kelly, K.M.; Sanga, P.; Zaki, N.; Wang, S.; Haeussler, J.; Louie, J.; Thipphawong, J. Safety and efficacy of fulranumab in osteoarthritis of the hip and knee: Results from four early terminated phase III randomized studies. Curr. Med. Res. Opin. 2019, 35, 2117-2127. [CrossRef] [PubMed]

17. Berenbaum, F.; Blanco, F.J.; Guermazi, A.; Miki, K.; Yamabe, T.; Viktrup, L.; Junor, R.; Carey, W.; Brown, M.T.; West, C.R.; et al. Subcutaneous tanezumab for osteoarthritis of the hip or knee: Efficacy and safety results from a 24-week randomised phase III study with a 24-week follow-up period. Ann. Rheum. Dis. 2020, 79, 800-810. [CrossRef]

18. Fuggle, N.R.; Cooper, C.; Oreffo, R.O.C.; Price, A.J.; Kaux, J.F.; Maheu, E.; Cutolo, M.; Honvo, G.; Conaghan, P.G.; Berenbaum, F.; et al. Alternative and complementary therapies in osteoarthritis and cartilage repair. Aging Clin. Exp. Res. 2020, 32, 547-560. [CrossRef]

19. Zeng, C.; Lane, N.E.; Hunter, D.J.; Wei, J.; Choi, H.K.; McAlindon, T.E.; Li, H.; Lu, N.; Lei, G.; Zhang, Y. Intra-articular corticosteroids and the risk of knee osteoarthritis progression: Results from the Osteoarthritis Initiative. Osteoarthritis Cartilage 2019, 27, 855-862. [CrossRef]

20. Aghamohammadi, D.; Dolatkhah, N.; Bakhtiari, F.; Eslamian, F.; Hashemian, M. Nutraceutical supplements in management of pain and disability in osteoarthritis: A systematic review and meta-analysis of randomized clinical trials. Sci. Rep. 2020, 10, 20892. [CrossRef] [PubMed]

21. Ansari, M.Y.; Ahmad, N.; Haqqi, T.M. Oxidative stress and inflammation in osteoarthritis pathogenesis: Role of polyphenols. Biomed. Pharmacother. 2020, 129, 110452. [CrossRef]

22. Oliviero, F.; Scanu, A.; Zamudio-Cuevas, Y.; Punzi, L.; Spinella, P. Anti-inflammatory effects of polyphenols in arthritis. J. Sci. Food. Argic. 2018, 98, 1653-1659. [CrossRef]

23. Schell, J.; Scofield, R.H.; Barrett, J.R.; Kurien, B.T.; Betts, N.; Lyons, T.J.; Zhao, Y.D.; Basu, A. Strawberries Improve Pain and Inflammation in Obese Adults with Radiographic Evidence of Knee Osteoarthritis. Nutrients 2017, 9, 949. [CrossRef] [PubMed]

24. Du, C.; Smith, A.; Avalos, M.; South, S.; Crabtree, K.; Wang, W.; Kwon, Y.H.; Vijayagopal, P.; Juma, S. Blueberries Improve Pain, Gait Performance, and Inflammation in Individuals with Symptomatic Knee Osteoarthritis. Nutrients 2019, 11, 290. [CrossRef] [PubMed]

25. Schumacher, H.R.; Pullman-Mooar, S.; Gupta, S.R.; Dinella, J.E.; Kim, R.; McHugh, M.P. Randomized double-blind crossover study of the efficacy of a tart cherry juice blend in treatment of osteoarthritis (OA) of the knee. Osteoarthr. Cartil. 2013, 21, 1035-1041. [CrossRef]

26. Connelly, A.E.; Tucker, A.J.; Tulk, H.; Catapang, M.; Chapman, L.; Sheikh, N.; Yurchenko, S.; Fletcher, R.; Kott, L.S.; Duncan, A.M.; et al. High-rosmarinic acid spearmint tea in the management of knee osteoarthritis symptoms. J. Med. Food 2014, 17, 1361-1367. [CrossRef] [PubMed]

27. Nguyen, C.; Boutron, I.; Baron, G.; Coudeyre, E.; Berenbaum, F.; Poiraudeau, S.; Rannou, F. Evolution of pain at 3 months by oral resveratrol in knee osteoarthritis (ARTHROL): Protocol for a multicentre randomised double-blind placebo-controlled trial. BMJ Open 2017, 7, e017652. [CrossRef]

28. Panahi, Y.; Rahimnia, A.R.; Sharafi, M.; Alishiri, G.; Saburi, A.; Sahebkar, A. Curcuminoid treatment for knee osteoarthritis: A randomized double-blind placebo-controlled trial. Phytother. Res. 2014, 28, 1625-1631. [CrossRef]

29. Heidary-Beni, M.; Moravejolahkami, A.R.; Gorgian, P.; Askari, G.; Tarrahi, M.J.; Bahreini-Esfahani, N. Herbal formulation "turmeric extract, black pepper, and ginger" versus Naproxen for chronic knee osteoarthritis: A randomized, double-blind, controlled clinical trial. Phytother. Res. 2020, 34, 2067-2073. [CrossRef] [PubMed]

30. Farid, R.; Mirfeizi, Z.; Mirheidari, M.; Rezaieyazdi, Z.; Mansouri, H.; Esmaelli, H.; Zibadi, S.; Rohdewald, P.; Watchon, R.R. Pycnogenol supplementation reduces pain and stiffness and improves physical function in adults with knee arthritis. Nutr. Res. 2007, 27, 692-697. [CrossRef]

31. Panahi, Y.; Alishiri, G.H.; Bayat, N.; Hosseini, S.M.; Sahebkar, A. Efficacy of Elaeagnus Angustifolia extract in the treatment of knee osteoarthritis: A randomized controlled trial. EXCLI J. 2016, 15, 203-210. [PubMed]

32. Farid, R.; Rezaieyazdi, Z.; Mirfeizi, Z.; Hatef, M.R.; Mirheidari, M.; Mansouri, H.; Esmaelli, H.; Bentley, G.; Lu, Y.; Foo, Y.; et al. Oral intake of purple passion fruit peel extract reduces pain and stiffness and improves physical function in adult patients with knee osteoarthritis. Nutr. Res. 2010, 30, 601-606. [CrossRef] [PubMed]

33. Levy, R.M.; Saikovsky, R.; Shmidt, E.; Khokhlov, A.; Burnett, B.P. Flavocoxid is as effective as naproxen for managing the signs and symptoms of osteoarthritis of the knee in humans: A short-term randomized, double-blind pilot study. Nutr. Res. 2009, 29, 298-304. [CrossRef] [PubMed] 
34. Karlapudi, V.; Prasad Mungara, A.V.V.; Sengupta, K.; Davis, B.A.; Raychaudhuri, S.P. A Placebo-Controlled Double-Blind Study Demonstrates the Clinical Efficacy of a Novel Herbal Formulation for Relieving Joint Discomfort in Human Subjects with Osteoarthritis of Knee. J. Med. Food 2018, 21, 511-520. [CrossRef]

35. Marlouf, B.H.; Hussain, S.A.; Ali, Z.S.; Ahmmad, R.S. Resveratrol Supplementation Reduces Pain and Inflammation in Knee Osteoarthritis Patients Treated with Meloxicam: A Randomized Placebo-Controlled Study. J. Med. Food 2018, 21, 12.

36. Bellamy, N.; Buchanan, W.W.; Goldsmith, C.H.; Campbell, J.; Stitt, L.W. Validation study of WOMAC: A health status instrument for measuring clinically important patient relevant outcomes to antirheumatic drug therapy in patients with osteoarthritis of the hip or knee. J. Rheumatol. 1988, 15, 1833-1840.

37. Dieppe, P.A.; Lohmander, L.S. Pathogenesis and management of pain in osteoarthritis. Lancet 2005, 365, 965-973. [CrossRef]

38. O'Neill, T.W.; Felson, D.T. Mechanisms of Osteoarthritis (OA) Pain. Curr. Osteoporos. Rep. 2018, 16, 611-616. [CrossRef]

39. Schaible, H.G. Osteoarthritis pain. Recent advances and controversies. Curr. Opin. Support. Palliat. Care 2018, 12, 148-153. [CrossRef]

40. Dimitroulas, T.; Duarte, R.V.; Behura, A.; Kitas, G.D.; Raphael, J.H. Neuropathic pain in osteoarthritis: A review of pathophysiological mechanisms and implications for treatment. Semin. Arthr. Rheum. 2014, 44, 145-154. [CrossRef]

41. Carlesso, L.C.; Segal, N.A.; Frey-Law, L.; Zhang, Y.; Na, L.; Nevitt, M.; Lewis, C.E.; Neogi, T. Pain Susceptibility Phenotypes in Those Free of Knee Pain with or at Risk of Knee Osteoarthritis: The Multicenter Osteoarthritis Study. Arthr. Rheumatol. 2019, 71, 542-549. [CrossRef] [PubMed]

42. Leong, D.J.; Choudhury, M.; Hirsh, D.M.; Hardin, J.A.; Cobelli, N.J.; Sun, H.B. Nutraceuticals: Potential for Chondroprotection and Molecular Targeting of Osteoarthritis. Int. J. Mol. Sci. 2013, 14, 23063-23085. [CrossRef]

43. Cisár, P.; Jány, R.; Waczulíková, I.; Sumegová, K.; Muchová, J.; Vojtassák, J.; Duraćková, Z.; Lisý, M.; Rohdewald, P. Effect of pine bark extract (Pycnogenol) on symptoms of knee osteoarthritis. Phytother. Res. 2008, 22, 1087-1092. [CrossRef] [PubMed]

44. Belcaro, G.; Cesarone, M.R.; Errichi, S.; Zulli, C.; Errichi, B.M.; Vinciguerra, G.; Ledda, A.; Di Renzo, A.; Stuard, S.; Duggal, M.; et al. Variations in C-reactive protein, plasma free radicals and fibrinogen values in patients with osteoarthritis treated with Pycnogenol. Redox Rep. 2008, 13, 271-276. [CrossRef]

45. Grimm, T.; Chovanová, Z.; Muchová, J.; Sumegová, K.; Liptáková, A.; Duracková, Z.; Högger, P. Inhibition of NF-kB activation and MMP-9 secretion by plasma of human volunteers after ingestion of maritime pine bark extract $\left(\right.$ Pycnogenol $\left.^{\circledR}\right)$. J. Inflamm. 2006, 3, 1. [CrossRef]

46. Schäfer, A.; Chovanova, Z.; Muchova, J.; Sumegová, K.; Liptáková, A.; Duracková, Z.; Högger, P. Inhibition of COX-1 and COX-2 activity by plasma of human volunteers after ingestion of French maritime pine bark extract (Pycnogenol ${ }^{\circledR}$ ). Biomed. Pharmacother. 2006, 60, 5-9. [CrossRef]

47. Levy, R.M.; Khokhlov, A.; Kopenkin, S.; Bart, B.; Ermolova, T.; Kantemirova, R.; Mazurov, V.; Bell, M.; Caldron, P.; Pillai, L.; et al. Efficacy and Safety of Flavocoxid, a Novel Therapeutic, Compared with Naproxen: A Randomized Multicenter Controlled Trial in Subjects with Osteoarthritis of the Knee. Adv. Ther. 2010, 27, 731-742. [CrossRef]

48. Levy, R.; Saikovsky, R.; Shmidt, E.; Khokhlov, A. Safety and efficacy of flavocoxid (Limbrel) compared with naproxen in subjects with osteoarthritis of the knee: A pilot study. Osteoarthr. Cartil. 2007, 15, B91-B94. [CrossRef]

49. Burnett, B.P.; Jia, Q.; Zhao, Y.; Levy, R.M. A medicinal extract of Scutellaria baicalensis and Acacia catechu acts as a dual inhibitor of cyclooxygenase and 5-lipoxygenase to reduce inflammation. J. Med. Food 2007, 10, 442-451. [CrossRef] [PubMed]

50. Clark, A.G.; Rohrbaugh, A.L.; Otterness, I.; Kraus, V.B. The effects of ascorbic acid on cartilage metabolism in guinea pig articular cartilage explants. Matrix. Biol. 2002, 2, 175-184. [CrossRef]

51. Sandell, L.J.; Daniel, J.C. Effects of ascorbic acid on collagen mRNA levels in short term chondrocyte cultures. Connect. Tissue Res. 1988, 17, 11-22. [CrossRef]

52. Ripani, U.; Manzarbeitia-Arroba, P.; Guijarro-Leo, S.; Urrutia-Graña, J.; De Masi-De Luca, A. Vitamin C May Help to Reduce the Knee's Arthritic Symptoms. Outcomes Assessment of Nutriceutical Therapy. Med. Arch. 2019, 73, 173-177. [CrossRef] [PubMed]

53. Zhang, Y.; Nevittt, M.; Niu, J.; Lewis, C.; Torner, J.; Guermazi, A.; Roemer, F.; McCulloch, C.; Felson, D.T. Fluctuation of knee pain and changes in bone marrow lesions, effusions, and synovitis on magnetic resonance imaging. Arthr. Rheum. 2011, 63, 691-699. [CrossRef]

54. Wang, Y.; Hodge, A.M.; Wluka, A.E.; English, D.R.; Giles, G.G.; O'Sullivan, R.; Forbes, A.; Cicuttini, F.M. Effect of antioxidants on knee cartilage and bone in healthy, middle-aged subjects: A cross-sectional study. Arthr. Res. Ther. 2007, 9, R66. [CrossRef]

55. Carr, A.C.; McCall, C. The role of vitamin C in the treatment of pain: New insights. J. Transl. Med. 2017, 15, 77. [CrossRef]

56. Li, H.; Zeng, C.; Wei, J.; Yang, T.; Gao, S.G.; Li, Y.S.; Lei, G.H. Associations between dietary antioxidants intake and radiographic knee osteoarthritis. Clin. Rheumatol. 2016, 35, 1585-1592. [CrossRef]

57. Chaganti, R.K.; Tolstykh, I.; Javaid, M.K.; Neogi, T.; Torner, J.; Curtis, J.; Jacques, P.; Felson, D.; Lane, N.E.; Nevitt, M.C. High plasma levels of vitamin $\mathrm{C}$ and $\mathrm{E}$ are associated with incident radiographic knee osteoarthritis. Osteoarthr. Cartil. 2014, 22, 190-196. [CrossRef] [PubMed]

58. Hanuka Katz, I.; Eran Nagar, E.; Okun, Z.; Shpigelman, A. The Link between Polyphenol Structure, Antioxidant Capacity and Shelf-Life Stability in the Presence of Fructose and Ascorbic Acid. Molecules 2020, 25, 225. [CrossRef] [PubMed]

59. Khalil, O.A.K.; De Faria Oliveira, O.M.M.; Vellosa, J.C.R.; De Quadros, A.U.; Dalposso, L.M.; Karam, T.K.; Mainardes, R.M.; Khalil, N.M. Curcumin antifungal and antioxidant activities are increased in the presence of ascorbic acid. Food Chem. 2012, 133, 1001-1005. [CrossRef] 
60. Millum, J.; Grady, C. The Ethics of Placebo-controlled Trials: Methodological Justifications. Contemp. Clin. Trials 2013, 36, 510-514. [CrossRef]

61. Adegbehingbe, O.O.; Adesanya, S.A.; Idowu, T.O.; Okimi, O.C.; Oyelami, O.A.; Iwalewa, E.O. Clinical effects of Garcinia kola in knee osteoarthritis. J. Orthop. Surg. Res. 2008, 3, 34. [CrossRef] [PubMed] 